\title{
A right ventricular rhabdomyoma in a child presenting with right ventricular outflow tract obstruction
}

\author{
Mustafa Yllmaz (D), Ulaş Kumbasar (D), Baran Şimşek (D), İlhan Paşaoğlu \\ Department of Cardiovascular Surgery, Medical Faculty of Hacettepe University, Ankara, Turkey
}

Received: April 11, 2017 Accepted: May 18, 2017 Published online: April 24, 2019

\section{ABSTRACT}

Primary tumors of the heart are extremely rare. Rhabdomyomas usually do not require any treatment, unless they cause outflow/inflow obstruction or conduction disturbances. Herein, we present an eight-year-old boy with a cardiac rhabdomyoma causing right ventricle outflow tract obstruction, which was successfully resected.

Keywords: Cardiac mass, rhabdomyoma, right ventricle.

Primary tumors of the heart are extremely rare with a prevalence rate of $0.01 \% \cdot{ }^{[1]}$ Rhabdomyomas are the most common benign primary cardiac tumors in children which regress spontaneously and usually do not require any treatment, unless they cause outflow/ inflow obstruction or conduction disturbances. Herein, we present an eight-year-old boy with a cardiac rhabdomyoma causing right ventricle outflow tract obstruction, which was successfully resected.

\section{CASE REPORT}

An eight-year-old patient was referred to our hospital with cardiac murmur. Physical examination findings were normal except a 3/6 systolic ejection murmur over his upper left sternal border. No abnormality was found on posteroanterior chest X-ray and electrocardiography. All routine blood tests were normal. Two-dimensional echocardiography revealed a $31 \times 27 \mathrm{~mm}$ echo-dense mass in the right ventricle originating from the interventricular septum and protruding through the right ventricular outflow tract (RVOT) (Figure 1).

A severe outflow obstruction with peak systolic pressure gradient of $60 \mathrm{mmHg}$ was found on Doppler examination. A median sternotomy incision was performed. Following initiation of cardiopulmonary bypass $(\mathrm{CPB})$ under mild systemic hypothermia, the heart was arrested with cold blood cardioplegia. Right ventriculotomy was, then, performed. Surgical examination revealed a $35 \times 35 \mathrm{~mm}$ round-shaped, pedunculated mass, originating from the interventricular septum and extending into the RVOT (Figure 2).

The mass was completely removed. Postoperative echocardiography was normal. The postoperative course of the patient was uneventful and he was discharged on postoperative Day 7. Histopathological examination of the specimen revealed a rhabdomyoma in which immunohistochemical stains showed the tumor cells to be positive for smooth muscle actin (SMA), desmin, and myoD1.

\section{DISCUSSION}

Among the rare congenital cardiac tumors, rhabdomyomas are the most common and are considered as benign myocardial hamartomas which are highly associated with tuberous sclerosis complex. ${ }^{[2]}$ However, physical examination findings of our case did not reveal an evidence of tuberous sclerosis.

Histologically, cardiac rhabdomyomas are welldemarcated nodules of enlarged cardiac myocytes

Corresponding author: Baran Şimşek, MD. Hacettepe Üniversitesi Tip Fakültesi Kalp ve Damar Cerrahisi Anabilim Dalı, 06100 Sihhiye, Ankara, Turkey.

Tel: +90 505 - 6972139 e-mail: simsekbaran@yahoo.com

\section{Citation:}

Yılmaz M, Kumbasar U, Şimşek B, Paşaoğlu İ. A right ventricular rhabdomyoma in a child presenting with right ventricular outflow tract obstruction. Cardiovasc Surg Int 2017;4(3):45-47. 


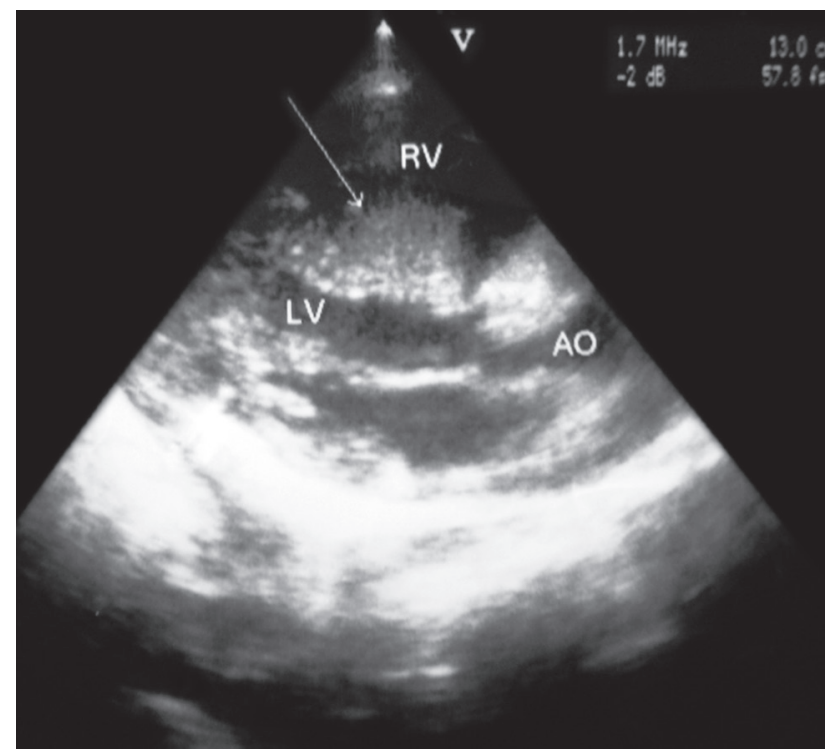

Figure 1. A preoperative echocardiographic view showing a $31 \times 27 \mathrm{~mm}$ echodense in the right ventricle originating from the interventricular septum and protruding through the right ventricular outflow tract.

which show ballooned out myofibers forming the typical "spider cells", which help to differentiate them from hamartomas of the mature cardiomyocytes. ${ }^{[2]}$

Rhabdomyomas may be totally asymptomatic, may present with an asymptomatic cardiac murmur as in our case, or may present with symptoms which include those related to valve obstruction or occlusion

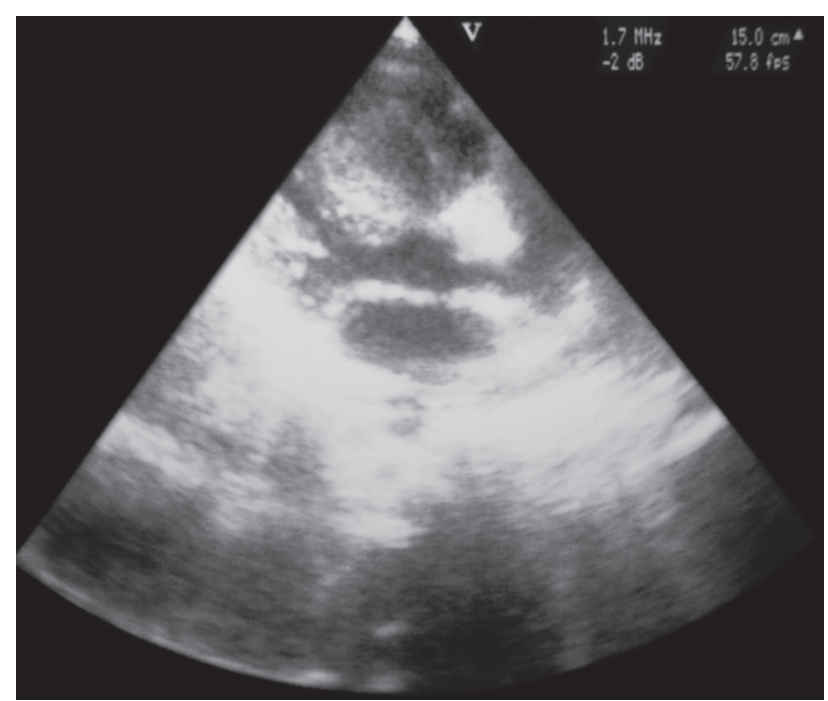

Figure 3. A postoperative echocardiographic view showing a mass-free right ventricle three days after surgery.

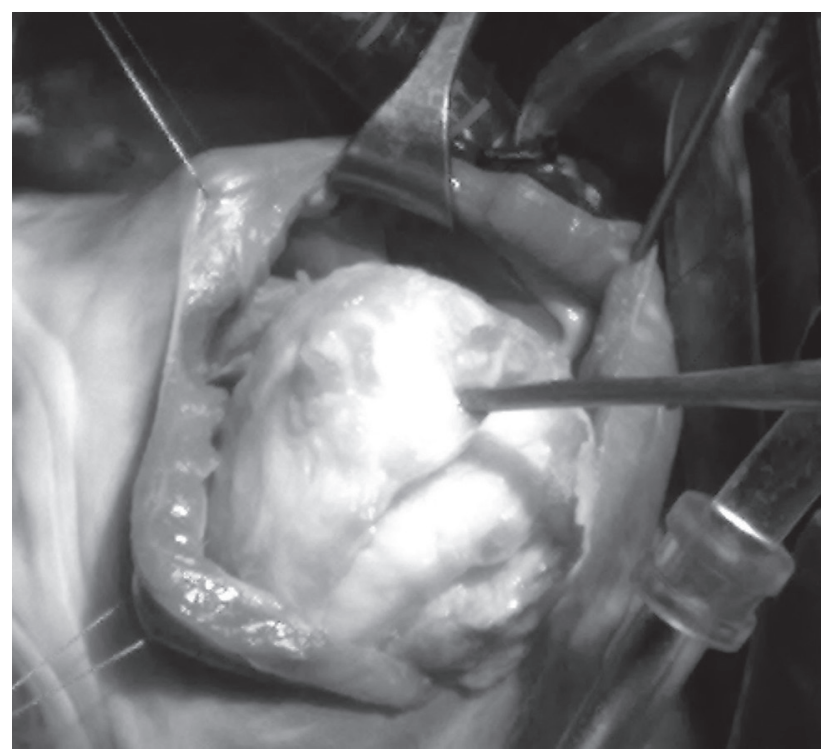

Figure 2. An intraoperative view showing a $35 \times 35 \mathrm{~mm}$ round-shaped pedunculated mass, originating from the interventricular septum and extending into the rightventricular outflow tract.

of chamber cavities, arrhythmias of various types and fetal hydrops. ${ }^{[3]}$ The tumors may cause infant respiratory distress, congestive heart failure or low cardiac output. Any chamber of the heart may be affected. The left ventricle is the most frequently affected site. The right-sided tumors which cause obstruction may cause cyanosis or features mimicking tetralogy of Fallot or pulmonary stenosis, left-sided tumors may present as subaortic stenosis or hypoplastic left heart syndrome. ${ }^{[4]}$

Echocardiography is a sensitive modality for the diagnosis of rhabdomyomas and shows relatively homogeneous well-circumscribed echo-bright masses. Cardiac magnetic resonance imaging or computed tomography are reserved for patients whom tumor type is questionable, for tumors that additional anatomical or functional information is required or for the evaluation of tuberous sclerosis. ${ }^{[5]}$

Furthermore, rhabdomyomas have a natural history of spontaneous regression and usually do not require any treatment. The indications for surgery include hemodynamic compromise due to obstruction of the cardiac chambers and intractable arrhythmias. Surgical removal of asymptomatic tumors is still controversial, as sudden death is also an important and ominous complication. The main goals of surgical 
treatment are the relief of the obstruction and the treatment of intractable arrhythmias. Total tumor excision is sufficient. ${ }^{[6]}$ While surgical resection of tumors causing RVOT obstruction is somewhat easier by the availability of a right ventriculotomy, left ventricular outflow tract obstruction remains surgically challenging as a retrograde approach through the aortic valve is limited by the size of the neonatal annulus. ${ }^{[7]}$

In conclusion, cardiac rhabdomyomas can be sporadic or associated with tuberous sclerosis or be seen with other cardiac malformations. They usually present early in life and indications for surgery are cardiac outflow obstruction, persistent arrhythmias, cardiac failure and cardiogenic embolism. Cardiac rhabdomyomas can be safely and completely resected. Surgical resection of right ventricular rhabdomyomas are technically easier than those originating from the left ventricle. Nonetheless, surgical resection is an adequate treatment in both cases.

\section{Declaration of conflicting interests}

The authors declared no conflicts of interest with respect to the authorship and/or publication of this article.

\section{Funding}

The authors received no financial support for the research and/or authorship of this article.

\section{REFERENCES}

1. McAllister HA Jr. Primary tumors and cysts of the heart and pericardium. Curr Probl Cardiol 1979;4:1-51.

2. Becker AE. Primary heart tumors in the pediatric age group: a review of salient pathologic features relevant for clinicians. Pediatr Cardiol 2000;21:317-23.

3. Venugopalan P, Babu JS, Al-Bulushi A. Right atrial rhabdomyoma acting as the substrate for Wolff-ParkinsonWhite syndrome in a 3-month-old infant. Acta Cardiol 2005;60:543-5.

4. Burke A, Virmani R. Pediatric heart tumors. Cardiovasc Pathol 2008;17:193-8.

5. Di Liang C, Ko SF, Huang SC. Echocardiographic evaluation of cardiac rhabdomyoma in infants and children. J Clin Ultrasound 2000;28:381-6.

6. Jacobs JP, Konstantakos AK, Holland FW 2nd, Herskowitz K, Ferrer PL, Perryman RA. Surgical treatment for cardiac rhabdomyomas in children. Ann Thorac Surg 1994;58:1552-5.

7. Black MD, Kadletz M, Smallhorn JF, Freedom RM. Cardiac rhabdomyomas and obstructive left heart disease: histologically but not functionally benign. Ann Thorac Surg 1998;65:1388-90. 